\title{
Parámetros esenciales de la obra artística
}

\section{Essential parameters of the artistic work}

Jesús Arreguin-Zozoaga ${ }^{a}$

\begin{abstract}
:
In human history, the need for expression and physical possession are key elements for the continuation of life. Communication consist of two basic branches; social and spiritual, which connect the human being to his equals as well as divinity, that is, creative and religious expression; human qualities that have coincided on his artistic work over the centuries. In this sense, part of the possible motivations that eventually lay on the artistic work, are briefly and generically stated.
\end{abstract}

Keywords:

Artistic work, artistic creation, cultural heritage, piece of art, ethics

\section{Resumen:}

En la historia general de la humanidad, la necesidad de expresión y de posesiones materiales son fundamentales para la continuidad de la subsistencia. La comunicación deriva lo social y espiritual en dos vertientes básicas que conectan al ser humano con sus congéneres y con lo divino, esto es, la expresión creativa y la religiosa; cualidades del ser humano que han convergido en su manifestación artística desde hace siglos. En este sentido, se plantean aquí brevemente y de manera genérica, parte de las posibles motivaciones que eventualmente subyacen en el quehacer artístico.

\section{Palabras Clave:}

Quehacer artístico, creación artística, herencia cultural, obra de arte, ética

\section{Introducción}

La impresión que se tiene de las cosas del mundo -la naturaleza y lo creado por nuestra civilización- está condicionada por las circunstancias, experiencias y voluntad de los individuos, para permanecer, pertenecer o disentir del contexto en el que crecen y se desarrollan. De la misma manera, la percepción del público respecto a las manifestaciones artísticas en general, radica en su capacidad de asociación de los elementos puestos en juego y del reconocimiento de los materiales disciplinares empleados; esto tiene que ver directamente con el grado de compenetración que tiene el espectador de arte con la manifestación artística a la que asiste o cultiva, y no obstante tenga un goce sensual e intuitivo del mismo, subyacen elementos culturales incluso psicológicos, que potencian negativa o positivamente la percepción que se obtiene de las obras artísticas.

\section{Desarrollo}

\section{Sobre la percepción de las cosas del mundo}

Sabemos que el ser humano está condicionado por diversos factores que modifican su comportamiento y por ende, su visión del mundo. La psique puede deducirse mediante patrones de conducta, como por circunstancias de índole neurofisiológica. Los acontecimientos trágicos o infaustos tienen efectos diversos en quien los sufre, y pueden experimentar situaciones angustiantes como desesperación y ansiedad que subyacen en la aparente estabilidad emocional. El estrés también puede influir en el estado anímico, manifestándose incluso como euforia a manera de válvula de escape de las tensiones.

La presión psicológica a la que alguien es sometido, puede generar paulatinamente, perturbaciones en la percepción y eventualmente desembocar en conductas diversas de la personalidad como: sumisión, depresión, soberbia, etcétera. Debido al grado de exposición a determinada presión o coerción, pueden resultar trastornos como: la paranoia y delirio entre otras en función de la fortaleza mental del individuo. Sin

a Autor de Correspondencia, Universidad Autónoma del Estado de Hidalgo, https://orcid.org/0000-0002-4785-0219, Email: arreguin_alarcon@hotmail.com 
embargo, en esas otras percepciones, también está la fantasia creativa en las artes; en la literatura se encuentran ejemplos de esta naturaleza en Poe, Lovecraft y Kafka entre otros. La psiquiatría contempla condiciones neurológicas sensibles y permanentes que suelen ser detonadas por impresiones fuertes: la esquizofrenia como la maniaco-depresión, llegan a potenciar las facultades humanas y no pocas veces los individuos que las padecen, logran realizar cosas que superan la capacidad media de las personas alcanzando estados de lucidez amplios, inclusive la percepción de visiones a partir de las cuales actúan.

En la historia de las religiones ha habido eventos cimentados en la intermediación divina, esto es, justificados a partir de la "revelación"; estados de conciencia que no le pertenecen a toda la gente, y que se ha argumentado provienen de una inspiración divina como el caso de Juana de Arco, o de Constantino que en el siglo IV aseveró la revelación de Cristo en sus sueños; ideó una contundente aplicación politico-religiosa con excelentes resultados, al proponer el domingo como día del Señor y el Pater Noster común, como apuntara Burkhardt (1945, pp. 331-338). Esta influencia es vigente en nuestros días:

\begin{abstract}
[...] Cristo podía pasar como un dios junto a los demás, y sus creyentes como súbditos junto a los creyentes en los dioses paganos. No negamos la posibilidad que en Constantino surgiera una cierta superstición a favor de Cristo, en tal forma que acaso estableciera una confusa combinación entre ese nombre y su dios solar; pero lo que le importaba era el éxito. [...] El emperador juró al obispo que no era cuento sino que vio de verdad aquella cruz en el cielo con la inscripción "con este signo vencerás" y que Cristo se le apareció en sueños, etc. [...] A este género pertenecen el día de domingo común y el Pater Noster común. "Instruyó a todos los ejércitos a honrar el día del Señor, que también es llamado día de la Luz y del Sol... también los paganos tenían que marchar en domingo al campo y elevar las manos pronunciando una oración, aprendida de memoria, en honor de Dios, autor de todas las victorias: A ti sólo te reconocemos como Dios y como Rey, a Ti sólo te imploramos como socorro nuestro. De Ti hemos recibido la victoria, gracias a Ti hemos vencido a los enemigos. A Ti te agradecemos el bien que hemos recibido y de Ti esperamos el bien que ha de venir. $A$ Ti te imploramos y rogamos para que nos conserves incólumes y victoriosos, por muchos años, a nuestro emperador Constantino y a sus hijos, amantes de Dios.
\end{abstract}

En el México Antiguo existe un paralelismo, mediante una intervención o invención, y que se constituyó en un hecho histórico en el ámbito politico-cultural con Tlacaélel (1398 d. C.), conocido como el artífice del Imperio Azteca -por haber sido consejero se soberanos mexicas y reformador religioso en los gobiernos de Itzcóatl, Motecuhzoma
Ilhuicamina y Axayácatl- a través de la "revelación" mítica del guerrero Tenoch con el símbolo del águila devorando una serpiente sobre un nopal, como señal para la fundación de la gran ciudad de Tenochtitlán. León-Portilla (1972, p.33)

La circunstancia de la revelación, presente en muchas culturas, argumentó la praxis de ritos y ceremoniales, cuyos efectos eventualmente generaron postulados religiosos, que influenciaron políticamente a la sociedad.

No debe sorprender que la política sea relacionada con el arte, polis (ciudad), proviene del griego y más específicamente de politiké techne (arte social o de vivir en sociedad, el arte de las cosas del Estado), por lo que es fácil deducir el tiempo que han estado relacionados. Recordemos sólo un segmento de la historia del arte de occidente que se consagró a lo religioso, de los albores del Renacimiento hasta el siglo XVIII por lo menos, así como a las diferentes civilizaciones que en términos generales hicieron lo mismo en sus distintas cosmovisiones.

Sin duda, la producción artística ha influido en la percepción del mundo, aunque se nos ha presentado por muchísimas décadas sólo como la visión social y contextual que realiza el "artista" de su entorno -como un "reflejo de la sociedad"- pero que moldea sin duda el interés público y perfila las políticas culturales, aunque sea de manera muy sutil.

\section{Coherencia entre lo que se piensa y lo que se hace}

Hay una gran diferencia entre lo que el individuo tiene que hacer, y lo que debe hacer: una cosa es realizar lo que le impelen hacer a uno, y otra, es realizar lo que se necesita hacer. El planteamiento tiene como primordial diferencia, la obligación de realizar algo en base a un tipo de responsabilidad, incluso impuesta, y la de la acción en base a principios que nos impelen por una normativa interna, de justicia social o dignidad, no obstante exista de por medio una imposición a no realizarla.

Es necesario reflexionar en los motivos de la actividad artística cuando se ejerce, pues aunque no parezca relevante, no es la misma proyección o alcance del quehacer artístico cuando se realiza por elección profesional que cuando lo es por convicción, y este planteamiento deriva un dilema respecto a las razones primordiales de dedicarse al arte.

Para los tlamatinime mexicas, el arte era como un "regalo de los dioses" que no debía desperdiciarse, y quién no lo ejercía o empleaba para el bien común -según su filosofía en la vida donde debía existir el equilibrio- merecía el 
desprecio por desperdiciarlo, y en ese caso, el incumplimiento a esa predestinación era prácticamente una maldición.

León-Portilla (2017, pp. 317), refiere en La filosofía náhuatl estudiada en sus fuentes lo siguiente:

Para llegar a ser como los toltecas, hacía falta estar predestinado a ello. Esa predestinación se manifestaba de doble manera. Por una parte era necesario poseer una serie de cualidades: ante todo ser "dueño de un rostro y un corazón", es decir, tener una personalidad bien definida. Además, [...] convenía haber nacido en una de las varias fechas que, según los conocedores del calendario adivinatorio, eran favorables a los artistas y a la producción de sus obras.

La alusión a los artistas, se infiere por la por intermediación de la herencia cultural heredada por los toltecas a quienes se les tenía en la más alta estima, y la personalidad bien definida al ser "dueño de un rostro y un corazón", es lo que en la actualidad podríamos interpreter como ética; esta percepción y sus conceptos esenciales, no están tan alejados después de 400 años, de la visión relativamente moderna que Weber tendría.

El sociólogo alemán Max Weber (1864-1920), realizó en Múnich el 28 de enero de 1919, La conferencia Politik als Beruf, que ha sido interpretada al español como: La política "como vocación" y "como profesión", Sánchez de la Barquera (2020, pp. 5-7) refiere que la palabra Beruf procede del alto alemán medio be-roufen (hablado entre 1050 y 1350 aproximadamente):

La raíz está en el verbo roufen (actualmente rufen, "Ilamar"), con el prefijo "be": berufen es tanto como nombrar o designar; Berufung es la vocación. En la Edad Media se hablaba de una vocatio interna y de una vocatio externa. Para los teólogos, se trataba en el primer caso de una vocatio spiritualis, es decir, la llamada procedente de Dios para dedicarse a una vida consagrada a él. [...] se separan la Berufung del Beruf, la vocación y la profesión. Por eso Weber define a la profesión (Beruf) como "esa especificación, especialización y combinación de capacidades de una persona y que forman el fundamento de una oportunidad continua de aprovisionamiento o de remuneración". [...] En la actualidad, la palabra alemana Berufung, vocación, es considerada un cultismo y una expresión anticuada, por lo que se usa Beruf / berufen para ambos casos, [...] pues en su texto habla de quien vive "de" la política y de quien vive "para" ella, utilizando siempre la palabra Beruf. La misma relación encontramos en el texto sobre "La ciencia como vocación". [...] en el primer caso, al vivir para ella, se da un sentido a la vida al dedicarla al servicio de algo elevado (lo que hemos mencionado arriba como vocatio interna); en el segundo caso, quien vive de la política se coloca en un nivel más bajo, más burdo -en un nivel económico-, pues depende de ella para vivir (la vocatio externa).

La vocación espiritual o el "llamado" y la actividad profesional como se acaba de observar, pone en escena la reflexión que deben tener los individuos respecto a la decisión de inclinarse por alguna actividad en particular.

La fuerza social y religiosa, impele al individuo a conducirse con sigilo para no estar fuera de ese contexto regulador; Berger (1971, p. 22) escribió: "El hombre crea valores y descubre que se siente culpable cuando los viola. El hombre construye instituciones que luego se enfrentan a él como poderosas estructuras controladoras y hasta amenazantes del mundo externo."

Por otra parte, Heschel (citado en Radhakrishnan y Raju, 1993, pp. 141-142), argumenta respecto a la fragilidad humana que:

\begin{abstract}
La esencia del hombre no está, efectivamente, en lo que es sino en lo que puede ser. Lo oscuro de la posibilidad es, sin embargo, el foco de la angustia. Hay que elegir siempre entre varios caminos y somos necesariamente libres -somos libres contra nuestra voluntad-y debemos tener la audacia de escoger, sabiendo apenas cómo o por qué. [...] Pero sólo los ojos vigilantes y fortificados contra lo brillante y superficial pueden percibir la visión [...]
\end{abstract}

Comparando esto con un fragmento de la Oración sobre la dignidad del Hombre de Giovanni Pico della Mirandola (1463-1494), veremos cómo el Hombre, especie virginal, debía construirse en sus inicios.

\begin{abstract}
[...] Tú, que no estás confinado por ningún límite, que serás conforme a tu propia y libre voluntad, en cuyas manos te hemos puesto, fijarás por ti mismo los límites de tu naturaleza. [...] No te hemos hecho de cielo ni de tierra, ni moral ni inmortal, para que, en libre elección $y$ honorablemente, como hacedor y modelador de ti mismo, puedas configurarte a ti mismo como prefieras. Tendrás el poder, gracias al juicio de tu alma, de remontarte a las formas más altas, que son divinas". (Herrera, 1972, pp. 232-233)
\end{abstract}

Esta es la descripción que tienen los individuos en un contexto social determinado, y que dependen únicamente de su propia percepción para actuar en él, por lo que su moral es su parámetro para poder integrarse al entorno, sin alterar entidades ni valores; es casi un estado de gracia. Entonces, ¿Cuándo aparece la conciencia y el juicio de valor de los actos que inciden en la percepción de las actividades de la vida?

Alfonso Reyes (1982, pp. 9-11) escribió al respecto:

El Hombre debe educarse para el bien. Esta educación y las doctrinas en que ella se inspira 
constituyen la moral o ética. [...] Todas las religiones contienen también un cuerpo de preceptos morales, que coinciden en lo esencial. [...] El bien no sólo se funda en una recompensa que el religioso espera recibir en el cielo. Se funda también en razones que pertenecen a este mundo. Por eso la moral debe estudiarse y aprenderse como una disciplina aparte. Podemos figurarnos la moral como una Constitución no escrita, cuyos preceptos son de validez universal para todos los pueblos y para todos los hombres. [...] El bien es un ideal de justicia y de virtud que puede imponernos el sacrificio de nuestros anhelos, y aún de nuestra felicidad o de nuestra vida. [...] Luego se ve que la obra de la moral consiste en llevarnos desde lo animal hasta lo puramente humano, pero hay que entenderlo bien. No se trata de negar lo que hay de material y de natural en nosotros, para sacrificarlo de modo completo en aras de lo que tenemos de espíritu y de inteligencia. [...] Lo que debe procurarse es una prudente armonía entre cuerpo y alma. La tarea de la moral consiste en dar a la naturaleza lo suyo sin exceso, y sin perder de vista los ideales dictados por la conciencia.

Respecto a la Moral y la Ética, el Dr. Enrique Dussel expresó en una entrevista (2019):

[...] La Cartilla [Moral] de Alfonso Reyes (1944), es antigua, es conservadora, [...] entonces tenemos que hacer otra... Hacia una nueva Cartilla pero ya no Moral, ético política [...] y ahora está actualizada al 2000 [2020], y entonces ya no es dualista, ya no es machista, ya no es eurocéntrica y está hablando a nuestro pueblo, y es otra cosa, es la ética, entonces hay que tomar muy en serio a la ética [...]

La filosofía moral o ética, valida los actos en virtud de las necesidades de los individuos, por lo que son un juicio de valor de su calidad humana. El filósofo Martin Buber (1993, pp. 128-129), concretiza de esta manera lo ético:

Hallamos lo ético en su pureza sólo allí donde la persona humana se enfrenta con su propia potencialidad y distingue y decide en tal confrontación, sin preguntar qué es lo bueno y qué lo malo en ésta, su propia situación. [...] Es el conocimiento por parte del individuo de lo que él es "en verdad", de qué está destinado a ser en su única y no repetible existencia creada.

De lo anterior, se podría referir que el más prístino ejercicio de la ética, sería como la virtud del equilibrio en todos los sentidos que se atribuye a los religiosos más legítimos; por lo que la ética sería el adalid para quienes no creen en otro tipo de existencia y por ello, tendrían que valorar las cosas con otra perspectiva.
En "Hacia una nueva cartilla ético política", Dussel (2020, pp.32-33), expresa que la ética es una cuestión de principios y no de valores; también puede percibirse que su planteamiento es similar al de Max Weber en "La política como vocación”, a 100 años de su concepción:

\begin{abstract}
La ética que proponemos por todo ello es una ética de principios y no de valores. Los principios son enunciados de deberes, de lo que debo o que tengo el deber de obrar; es decir, es una obligación. Puede o no cumplirse la obligación, obrarla o no, pero si no hago lo que debo pongo en peligro mi vida (o algún aspecto de ella) y la vida de la comunidad. Es una exigencia que tengo que operar para mi bien y para el bien de la comunidad. No es algo que si no cumplo, y nadie se entera, no tendrá ninguna consecuencia. No. Si no cumplo lo que debo obrar, en último término personal y comunitariamente, pongo en riesgo la vida: es una cuestión de vida (el bien, la justicia) o la muerte anticipada (el mal, la injusticia).
\end{abstract}

Así mismo -como apuntamos al inicio de este apartado en el contexto del toltecáyotl, ensalzado por los tlamatinime prehispánicos- se evidencia también, un paralelismo en conceptos y valores, atribuidos a los artistas.

En la proliferación del arte occidental marcado por la revaloración del pasado, el Renacimiento en Italia filtró a la luz parte de la herencia de muchas civilizaciones del Arte Antiguo, y comenzó a establecer parámetros estéticos a partir de la recuperación y sistematización de la producción precedente, y en particular de la griega. Ese período propició también la reestructuración del pensamiento en otros principados, estados y monarquías; y la actividad artística se llegó a concebir como el ejercicio de una habilidad y el desarrollo de ella, es decir, como un oficio, del latín officium "servicio, función" derivado de opifex, opificis "artesano" formado de opus (obra) y facere (hacer) y el sufijo -io (acción y efecto). En función de la perfección de esa habilidad, cambió su denominación a lo que conocemos como arte, y ese desarrollo no sólo sucedió por la maestría en su ejecución, fue necesario el perfeccionamiento de la percepción estética y la técnica. Evidentemente, esto derivó una serie de reglas y parámetros teórico-técnicos que el artista tenía que aplicar en la obra a nivel personal y posteriormente, ya sistematizados, a un nivel generalizado. Ejemplo conocido de esta situación, son los talleres de pintura y de ebanistería, entre otros, que los artistas y artesanos tenían, y la adquisición que la nobleza eventualmente hacía de su obra, cuyos trabajos eran valorados básicamente por la calidad de su factura derivada de la praxis, es decir, de la experiencia en su oficio y maestría alcanzada. Curiosamente, el nombre de la antigua "galería de las oficinas" en Florencia, Italia, La Galleria degli Ufizzi, es una derivación etimológica de 
officium, y alberga una cantidad enorme de obras de arte pertenecientes originalmente a los Medici.

El noble quería ser bien representado, la dignidad de su nobleza casi siempre fue rebasada por sus posesiones; fue el artista quien tuvo la necesidad de plasmar sus emociones y motivaciones, la necesidad de que su obra tuviera algo de sustancia, un ánima, independiente de la espiritualidad institucional. No olvidemos que los grandes genios de la música como Bach y Mozart entre otros, eran considerados como sirvientes, pero pudieron filtrar sus necesidades artísticas dentro de su música, sin que de ello se percataran sus patrocinadores, otrora mecenas. Recordemos que históricamente la nobleza y la iglesia también han procurado a la ciencia y las artes, quien no tuviera en esos tiempos de su esplendor la capacidad de desempeñarse en esos ámbitos, tenía que sobrevivir como pudiera, morir de hambre, formar parte del ejército, ser caballero o su escudero, o tomar los hábitos.

Por lo expresado antes, no debemos olvidar que el término oficio viene de una vocación, y que se refiere a la habilidad de realizar una actividad específica y que su perfeccionamiento deriva en su profesionalización (probablemente es aquí donde con el tiempo, se genera la corruptela del término), y también señalar, que el término de "profesional" no se aplica a la calidad artística de las personas, sino a su desempeño en lo que hacen y es aplicable a cualquier actividad o profesión. El siglo XIX generó al director de orquesta como una profesión o especialidad derivada de la necesidad que tenía el compositor para que su música se escuchara; los compositores R. Strauss y G. Mahler dieron gran impulso a la dirección orquestal al grado de convertirse en grandes referentes, aunque los compositores de siglos precedentes dirigían sus propias obras.

Precisando lo anterior, la profesión viene de una elección entre varias opciones -incluso por necesidad- y la vocación, de una habilidad natural predispuesta por la naturaleza. En la modernidad podemos escoger una profesión por múltiples razones -del latín professio, -onis, "acción y efecto de profesar"- y que para su ejercicio se requiere de estudios universitarios y al ejercerse se recibe una retribución por ello, pero en las artes que se basan en la práctica, además de los estudios necesarios se requiere tener la vocación -del latín vocatio "Ilamado o ser llamado" a una determinada empresa- es un reclamo a vivir para ella, por lo que debe realizarse con convicción pues es innata, hay quienes piensan que es casi una cualidad del espíritu -se entiende que quienes se dedican a la medicina también la tienen- en ciertas especialidades de la medicina y por la vocación que muestran en tal desempeño, se les llega a denominar como médicos del alma. Podría decirse que la vocación es un "don", y es triste dedicarse a algo para lo que no se es llamado, o tener que impostar una personalidad, o comulgar con la apariencia.

\section{El gusto y el recuerdo como base de un parámetro estético en el arte}

Si bien puede explicarse psicológica o socialmente la conducta humana en función de los antecedentes vivenciales, también podría decirse lo mismo sobre la propensión a ciertas cosas de la vida como a la inclinación artística, y en este sentido, podríamos pensar en la adhesión estética, por ejemplo, en la organización de los elementos de una disciplina en particular. Aunque el trabajo en la construcción de un conocimiento es fuerte, también depende de la comodidad o facilidad que este implica, en función del ejercicio de sistematización o modo de operar en él, es decir, del tiempo de dedicación o interacción con esa determinada actividad. La continuidad en el ejercicio de dicha sistematización disciplinar, deviene en lo que se podría entender como estilo personal.

Reflexionando un poco esto, existe una relación intrínseca entre dos aspectos que pueden influir en la inclinación estética del individuo y que aparentemente tendrían que ver muy poco entre sí: el gusto y el recuerdo por algo, binomio que tiene un punto que los une en la distancia del tiempo. Estas dos percepciones están soterradas en los eventos emocionales y temporales de la memoria; conceptos distintos, pero sutilmente unidos mediante la emotividad de los afectos y de la cualidad psicológica de la que están dotados.

La remembranza del pasado no viene sola, su evocación trae consigo un tamiz o envolvente emocional y contextual que en el mejor de los casos puede ser agradable e inducir nostalgia, como también puede ser incómoda o dolorosa, incluso aberrante hasta la negación del recuerdo mismo en función de la madurez que se tenga para contextualizar aquello que se rememora. Por otra parte, ese binomio podría ocultar también la conveniencia.

\footnotetext{
... no existe herencia material que no sea a la vez una herencia cultural, y los bienes familiares tienen como función no sólo la de dar testimonio físico de la antigüedad y continuidad de la familia y, por ello, la de consagrar su identidad social, no disociable de la permanencia en el tiempo, sino también la de contribuir prácticamente a su reproducción moral, es decir, a la transmisión de los valores, virtudes y competencias... (Bordieu, 1979, p. 75)
} 
Así, aquello que puede caracterizarse como "aceptable" para alguien, es muy probable que esté impregnado de la afectividad ubicada en las situaciones gozosas del pasado, o simplemente en el ámbito de las vivencias y costumbres instauradas como un hábito; un contexto al que se es particularmente sensible (en el presente), y que "se conecta" con el subconsciente del individuo, relacionando así en reciprocidad de jerarquías el valor y la belleza.

Esta conexión psicológica -como quantum perceptivose manifiesta generalmente por inducción exógena, es decir, la información del subconsciente detonada por un estímulo, no sólo por la remembranza a priori que se puede establecer. Existe la percepción cruzada donde un estímulo sonoro detona una percepción visual por ejemplo, que es una de las variedades más comunes de esta cualidad catalogada como sinestesia neurofisiológica. Así, la elección estética o adhesión a un tipo de sistema de operar en particular, puede estar afianzada en la tradición como reconocimiento o identificación de algo y su proyección en las vivencias.

Obviamente, no se excluyen la voluntad y percepción personal, para el desarrollo de un determinado oficio y la adquisición de una técnica particular con todo el rigor disciplinar, pero esta obedece a otra categoría que se relaciona con la convicción y decisión personal en términos de la percepción del desarrollo del arte.

En el ámbito de la música "seria" o "académica" aún sigue empleándose el término oficio, para decir que alguien tiene preparación seria en lo que hace, también algunos lo denominan como técnica. Hace pocos años se usaba también como sinónimo de calidad o seriedad en las artes plásticas, pero también se ha circunscrito a algunos reductos, pues ahora se han diversificado las artes visuales.

Es curioso que actualmente en las artes, se empleen de manera coloquial "conceptos" como: bueno, interesante, capacidad y talento, para difuminar o evadir la responsabilidad de juzgar la calidad de una obra o la preparación del individuo; aunque es posible también, que sea debido a la mutación del lenguaje, pues su modernización va adecuando lo preexistente.

Por lo general, el juicio de valor que se hace de las cosas, tiene la carga inmanente de las propias experiencias y sus expectativas. Pareciera que sólo una parte de las elecciones que el ser humano hace en la vida obedecen a condiciones racionales puras, lo que no necesariamente significa que guste o no de ellas.

"La importancia del placer es variable en el arte [...] el arte absorbe plenamente el placer en el recuerdo y en el deseo", diría Adorno (1983, p. 26-27).

Ejemplo de esto, puede ser el pulso cardíaco referido como proyección ontológica de la experiencia sonora y rítmica de los tambores, en donde una sencilla secuencia y poderío textural bastan para capturar al escucha por su reconocimiento y energía. Esa secuencia o repetitividad, evoca situaciones rituales y extáticas prácticamente arquetípicas como un eslabón emotivo para el inconsciente, o un parámetro de empatía antropológica, que eventualmente sirve como puente de gran impacto social en la música popular, y de otros géneros o "circuitos de la música" (Foucault, M. y Boulez, P. 1985), pues son parte fundamental de su esencia y posible éxito. Como individuos en un contexto que nos envuelve e involucra sin necesariamente compartir una serie de condiciones, estamos inmersos o permeados de él como parte de la mecánica socio-cultural o idiosincrática que hace que esta se mueva, “...el mundo social constituye un nomos [un orden significativo], tanto objetiva como subjetivamente" (Berger, 1971, p. 34). No obstante, es claro que la percepción del mundo depende de la personalidad del individuo así como de su circunstancia y que estamos condicionados en mayor o menor grado a lo que vivimos en nuestra infancia, según la relevancia, el tiempo y el impacto de lo vivido.

\section{La percepción del arte}

En el arte en general, existe cualquier cantidad de parámetros conceptuales para diseñar una obra, desde el filosófico hasta el matemático en los que interactúan una serie de relaciones interconectadas o asociativas entre los elementos empleados que, aunque no se perciban, pueden filtrarse subconscientemente o a través de relaciones simbólicas inferidas en quien atiende el fenómeno artístico. Un detalle o relación, de las tantas posibilidades de estructuración en las propuestas artísticas, puede incidir ampliamente en el sentido conceptual y expresivo de las mismas.

Como sabemos, muchas obras pueden ser reinterpretaciones del pasado, de lo que escribieron y dijeron otros; la idea sobre algún tema determinado, abordada constantemente por diferentes voces va solidificando lo primigenio o aquello que quizá en algún momento sólo era un atisbo o suposición. Las necesidades espirituales, artísticas y científicas han llamado la atención de las generaciones pasadas y contemporáneas, y como objetos de estudio, se convierten en señales o luces para observar su desarrollo en el futuro. Pareciera que los grandes temas de la humanidad siguen siendo los mismos, pero con otro enfoque, y es precisamente esa perspectiva la que puede 
y debe marcar la diferencia con la producción de un determinado tiempo. Desde el pasado se ha ponderado el valor del arte en función de su conexión con el entorno, desde lo contemplativo, subjetivo e intelectual, hasta su aplicación social. Mucho del arte contemporáneo no ha evolucionado únicamente, sino que ha extralimitado y extrapolado los valores y jerarquías antes relevantes, no obstante, habrá de someterse de igual manera al tiempo y al juicio de sus especialistas (para juzgarlo), pues el arte siempre tiene parámetros suficientes que lo sustentan como tal.

Existe la adhesión, inercia o condicionamiento social al cultivo de tipologías estéticas que incluso pueden ser autoimpuestas, y aunque el arte no tiene una función específica, si tiene sus resquicios y no siempre es totalmente libre como se podría suponer.

El hacedor de arte -quien se dedica a la creación artísticapondera bajo sus propios conceptos los relieves que desea imprimir a su obra; esta aseveración parece obvia, no obstante, no siempre realiza todo lo que desea y eventualmente lucha consigo mismo respecto a sus intereses. El artista suele decidir entre la convención, la convicción, la naturaleza de la obra misma y el compromiso con el acto creativo.

La creación artística -la manifestación creativa u obra- en su más prístina manifestación, tiene al centro de su legitimidad y valor, la cristalización de las ideas de su creador sin más pretensiones que su proyección fijada en el medio de soporte disciplinar específico.

Habrá quienes eventualmente experimenten la incomprensión ante un evento u obra artística, pero eso es parte de las condiciones en las que radica su libertad y riqueza, en la apertura a múltiples interpretaciones y exploración del objeto de estudio. Es importante no olvidar que así como existe la genialidad incuestionable, también está la intuición incomprensible que eventualmente se revela en la obra misma y puede escapar a la comprensión de quienes la presencian. Sin embargo, no se debe olvidar que existen algunos parámetros básicos que por sí mismos pueden legitimar la obra, independientemente de los más sutiles patrocinios como del impulso que su creador le confiera, tanto del punto de vista estético como del conceptual, en un marco de referencia temporal y contextual.

Muy pocas veces se refieren los parámetros que podrían ser un indicio para valorar una obra artística, pues se piensa que son subjetivos o pretenciosos y se categorizan como tabú, no obstante, sería pertinente mencionar en este espacio y en términos generales, algunos de ellos a manera de indicio o sustento al momento de apreciar o dirimir respecto al arte.

Se asume de lo general a lo particular y en base al proceso histórico, que la obra de arte debe reflejar parte de la realidad o certidumbre de una comunidad, estos aspectos pueden ser cotidianos o de una idea compartida en la vida, y de ahí su impacto, una especie de común denominador.

No es gratuito que las obras de arte de todos los tiempos representaran a la Divinidad en sus múltiples acepciones o manifestaciones y tampoco significa que esa fuera su única temática, ni tenga porque serlo en la actualidad.

Evidentemente, el Arte ha progresado a través del tiempo y sus técnicas como sus temas han integrado otros parámetros de experimentación, señalamientos y tecnologías. Coexisten ciertos criterios que aún perfilan a la obra de arte: el dominio técnico mostrado en la obra, es lo que sustenta en términos generales el rigor de su factura y gran parte de su valor radica en la riqueza y aportación de lo que esta propone; es deseable que estas condiciones estén "idealmente" dispuestas en las dimensiones de sus elementos de fijación como son el espacio físico, auditivo y el de las ideas y demás. Así, tenemos que el punto de su cristalización es cuando todos los parámetros empleados llegan a la Unificación de la propuesta creativa. Eventualmente -y de manera parcial en el transcurso del tiempo- ésta es validada por los especialistas, el reconocimiento social por su impacto producido, el "paso del tiempo" y una "dosis de misterio"; estos criterios a grosso modo, le adjudican a una obra en particular la distinción de obra de arte (fuera de los términos del "objeto"), y en grado superlativo, la de obra maestra.

El equilibrio técnico, formal y conceptual generalmente son los aspectos constitutivos de la calidad de una obra, y en ese sentido, nos permitimos expresar que esa contiene -al menos desde nuestro particular punto de vista- los siguientes parámetros:

La Propuesta, que sería lo que nos quiere dar a entender o mostrar la obra, lo que plantea la postura personal del creador en base a su reflexión. La Proyección de la obra, que puede irradiar de lo particular a lo general o viceversa, es decir, sus alcances en base al contenido.

\section{El Reconocimiento 0}

identificación mínima de los elementos empleados en su elaboración, de los cuales pueda asirse aunque sea parcialmente el espectador y que le proporciona cierta pauta de lo planteado. La Aportación que hace la obra en base a la originalidad, novedad o innovación en alguno de sus elementos constitutivos, es precisamente uno de los parámetros más valiosos y que puede ser tanto en el ámbito conceptual como en el técnico. 
La Factura de la obra, es decir, lo que se circunscribe prácticamente al ámbito técnico de la manipulación de los elementos disciplinares y que por supuesto, se integra con la seriedad de la propuesta conceptual que se presenta.

La Forma o Estructura es una referencia relativamente subjetiva, pero que sin duda se fundamenta en un balance adecuado de todos los elementos puestos en juego en la obra, de tal manera que ciertos parámetros no rebasen o interfieran con otros, desde los específicamente técnicos y emocionales, hasta los aspectos psicológicos, sensoriales e incluso temporales, entre otros.

Podría decirse que la obra fundamentada en estos parámetros artísticos es en esencia una tesis.

Sabemos que existen obras técnicamente muy bien realizadas pero sin gran contenido y viceversa, algo parecido a un gran actor con un guion pobre o una interpretación musical técnicamente limpia o sin errores, pero sin proyección emotiva o viceversa. También, se llega a verificar la ideación de conceptos ingeniosos que no alcanzan la seriedad para su denominación como arte, y se intenta por antonomasia su reconocimiento. La idea es importante, pero por sí misma no alcanza la proyección suficiente para validar a una obra como relevante sólo por el concepto, aunque evidentemente pueda influir a otros creadores y que inclusive puedan desarrollarla.

La cualidad emotiva en la representación artística era valiosa, incluso necesaria, pero la evolución del arte ya puede prescindir de ella y no hay problema pues la belleza redimensionó sus implicaciones.

El arte al que nos referimos no es sólo al de la seducción, es al de la reflexión y desarrollo de las ideas transferidas -y fundamentadas en la práctica- a nuestras extremidades, que en el caso de la literatura o la poesía se fijan en el papel, la música en la partitura, la danza en la coreografía, las artes plásticas y visuales en sus materiales específicos, el drama en escena, y muchas más manifestaciones que también desde hace mucho tiempo, se fijan en medios digitales y auditivos.

\section{Conclusión}

Es necesario tener cuidado con la designación que se otorga a la producción artística, pues paulatinamente se ha aligerado el valor de la obra -en cuanto a la calidad de su factura- gracias a un ecumenismo mal entendido en donde se da sin un análisis serio, la "validación" a toda la producción, únicamente por situarse en el concepto inicial de que el arte es todo aquello realizado por los humanos, a excepción de la natura. En base a ese criterio, asistimos a un estado equivalente a la catalogación que se ha hecho de la producción artística previa al denominado Arte Antiguo, en donde casi todos los objetos realizados por el humano, adquierieron por antonomasia la denominación de arte.

\section{Referencias}

[1] Adorno, T. (1983). Teoría Estética, El goce artístico, trad. Fernando Riaza, revisión de Francisco Pérez Gutiérrez. Orbis, S. A., España.

[2] Berger, P. (1971). El Dosel Sagrado. Para una teoría sociológica de la religión. Kairós. Barcelona España.

[3] Bourdieu, P. (1979). La distinción Criterios y bases sociales del gusto, trad. Ma. del Carmen Ruiz. Taurus. España.

[4] Buber, M. (1993). Eclipse de Dios. Estudios sobre las relaciones entre religión y filosofía. FCE. México.

[5] Burckhardt, J. (1945). Del Paganismo al Cristianismo. FCE. México.

[6] Dussel, E. (2019). Dr. Enrique Dussel en Aristegui Noticias para hablar de la situación actual de México y su gobierno. [Canal: Enrique Dussel]. Recuperado el 10 de agosto de 2020 desde: https:/www.youtube.com/watch?v=VQtOay7elk8

[7] Dussel, E. (2020). Hacia una nueva cartilla ético política. Ed Enrique Dussel. pp. 96. Recuperado el 12 de septiembre de 2021 desde:

https://mega.nz/folder/hkATgQZR\#1W1JjpkJB0aTesGRcULh6w

[8] Foucault, M \& Boulez, P. (1985). EXCERPTER.

Contemporary Music and the Public. Perspectives of New Music, 24 (1 Fall-Winter), pp. 6-12. Recuperado el 17 de noviembre de 2018 desde: https://excerpter.wordpress.com/2005/12/24/michelfoucault-pierre-boulez-contemporary-music-and-the-public/

[9] Herrera, A. (1972). Antología del Renacimiento a la Ilustración. Universidad Nacional Autónoma de México (Colegio de Ciencias y Humanidades). México.

[10] León-Portilla, M. (1972). Trece poetas del mundo azteca, 1ra. Ed. SEP/SETENTAS. México.

[11] León-Portilla, M. (2017). La filosofía náhuatl estudiada en sus fuentes Universidad Nacional Autónoma de México, Instituto de Investigaciones Históricas, p. 526. Recuperado el 20 de septiembre de 2021 desde:

https://www.historicas.unam.mx/publicaciones/publicadigital/libr os/filosofia/046_04_35_concepcion_nahuatl.pdf

[12] Radhakrishnan. S., y Raju, P. (1993). El Concepto del Hombre, estudio de filosofia comparada, trad. Julieta Campos y Juan José Utrilla. FCE. México.

[13] Reyes, A. (1982). Cartilla moral. Asociación Nacional de Libreros A. C. México. 
[14] Sánchez, H. (2020). "La política como vocación”. Un

estudio preliminar a cien años de distancia. Universidad Nacional

Autónoma de México, Instituto de Investigaciones Jurídicas, pp.

1-14. Recuperado el 20 de septiembre de 2021 desde:

https://archivos.juridicas.unam.mx/www/bjv/libros/13/6032/4.pdf 